\title{
Clutch-Starting Stalled Research Students
}

\author{
Kathy Ahern and Catherine Manathunga
}

\begin{abstract}
Many research students go through periods where their research seems to stall, their motivation drops, and they seem unable to make any progress. As supervisors, ${ }^{1}$ we attempt to remain alert to signs that our student's progress has stalled. Drawing on cognitive strategies, this article explores a problem-solving model supervisors can use to identify the major causes of the student's lack of progress and facilitate the student's re-ignition. Each of the problem identification and solving phases is acknowledged by and situated within research on postgraduate supervision and supported by analyzing transcripts from a study on postgraduate supervision.
\end{abstract}

KEY WORDS: academic procrastination; research students; supervisors; graduate study.

Since the 1970s, university and governmental concerns about the declining rates of timely completions among research higher degree students (especially doctoral students) have generated many studies into the factors predicting successful and timely completions. In Australia, groups such as the Federal Government Department of Education, Science and Training (DEST) have called for the improvement of timely completion rates by introducing more comprehensive supervisor training and by improving postgraduate students' inclusion in research cultures within university research centers and schools (Deem \& Brehony, 2000). Often postgraduate research students go through periods where their research seems to stall, their motivation drops, and they seem unable to make any progress. Although this type of stalling may occur at any time during their period of study, research and anecdotal evidence suggest that a prime time for this experience is during the middle of the program (Parsloe, 1993). As supervisors, we attempt to remain alert to signs that our student's progress has

Kathy Ahern received her Ph.D. in Human Movement from The University of Western Australia. She is currently a Lecturer in the School of Social Science, The University of Queensland, Australia. Her research interests include child and adolescent mental health. Catherine Manathunga received her Ph.D. in History from The University of Queensland. She is currently a Lecturer in Higher Education in the Teaching and Educational Development Institute/The Graduate School, The University of Queensland, Australia. Her research interests include postgraduate supervision, interdisciplinary research, the scholarship of academic staff development, and research-led teaching.

1 "Supervisor" is the Australian and United Kingdom equivalent of the terms advisor or major professor in the U.S. It refers to the academic who supervises research or graduate students' theses. 
stalled and to provide appropriate action to get the student back on track.

In order to help our students through these difficulties, we have developed a visual model of our problem-solving strategy that explores potential cognitive, emotional, and social factors that may cause students to stall.

In this article we explain the factors and the solutions we and other supervisors use to unblock stalled students. We draw upon our experiences, the burgeoning literature on postgraduate supervision, and a University of Queensland study into detecting and dealing with warning signs (Manathunga, 2002).

\section{Identifying Stalled Students}

The process of identifying the factors behind a student's lack of progress starts by picking up cues that the student is not progressing satisfactorially, and it is indeed possible to identify warning signs. Research into how expert supervisors detect and deal with warning signs that their research students are experiencing difficulties was recently conducted at the University of Queensland (Manathunga, 2002). This study indicated that these warning signs center around four key types of behaviour:

- constantly changing the topic or planned work,

- avoiding all forms of communication with the supervisor,

- isolating themselves from the department and from other students,

- and avoiding submitting work for review.

More specific signs of the first two types of behaviour included continually broadening or altering the proposed topic of research, failing to keep appointments, not answering communications, and generally avoiding contact with the supervisor. Avoiding communication can also impact upon the student's overall relationship with other members of the department and other students (Bill, ${ }^{2}$ interview). Avoiding submitting work for review mainly involves finding ways of avoiding writing. These included taking too much time with other work, particularly teaching;

\footnotetext{
${ }^{2}$ Semi-structured interviews were conducted with eight supervisors (4 females and 4 males) from a range of disciplines at The University of Queensland as part of a study into detecting and dealing with warning signs in postgraduate research education (Manathunga, 2002). Focus groups were also conducted with 45 students from a cross-section of disciplines and a range of stages in their Ph.D. studies. To preserve the anonymity of these supervisors and students all the names have been changed.
} 
over-reading or collecting more and more experimental or field data in lab/field-based research; and resubmitting old work instead of working on new chapters or sections of work (Interviews). The common features of all of these warning signs were displays of anxiety, sometimes resulting in quite marked changes in students' behaviour or appearance (Interviews).

These key types of behaviour involve what Rothblum, Solomon, and Murakami (1986) called academic procrastination. They defined academic procrastination as the "tendency to (a) always or nearly always put off academic tasks, and (b) always or nearly always experience problematic anxiety associated with this procrastination" (Rothblum, Solomon, \& Murakami, 1986, p. 387). The value of this definition is that it not only describes the behaviour of some stalled students; it also highlights the negative effects of such behaviour (Ferrari \& Beck, 1998). If procrastination leads to anxiety, then the sooner it is addressed, the better. In other words, a wait and see approach to student avoidance behaviour might be less confronting to a supervisor than addressing the problem, but research indicates that this type of non-action by a supervisor exacerbates the student's problems.

A U.S. study by Johnson, Green and Kluever (2000) specifically explored procrastination in doctoral students. They had developed a Procrastination Inventory based on an earlier instrument used by Muszynski and Akamatsu (1991). Johnson et al. (2000, p. 275) analysed the results after administering this inventory to graduates and what U.S. commentators call ABD (All But Dissertation) students in an Education program through the use of three subscales: procrastination; perfectionism; and graduate school comfort (fear of separation from the graduate school). They found that ABDs had higher levels of procrastination and perfectionism than graduates, although graduate school comfort did not emerge as a significant factor. They recommended the use of the Procrastination Inventory as a tool for identifying and assisting students more likely to procrastinate in their studies. In an Australian context, Kearns (2002) explored the prevalence of selfsabotage among research higher degree students at Flinders University. He found that the key self-sabotaging behaviours also included procrastination, perfectionism, and overcommittment to other activities.

Many of the reasons for academic procrastination are related to a fear of failure (Solomon \& Rothblum, 1986). These include general anxiety, performance anxiety, perfectionism (as indicated above), low frustration tolerance, inability to accept help, low self-esteem, and lack of selfconfidence (Beswick, Rothblum, \& Mann, 1988; Johnson et al., 2000; 
Solomon \& Rothblum, 1984). Further reasons for academic procrastination include experiencing problems with what a number of researchers have called academic self-regulation (Black \& Deci, 2000; Schapiro \& Livingston, 2000; Senécal, Koestner, \& Vallerand, 1995). These researchers found that students who had intrinsic reasons for pursuing their studies such as an interest in the topic were likely to procrastinate less, whereas those who had extrinsic reasons were likely to procrastinate more. They suggested that supervisors look beyond the fear-of-failure construct when considering motivational explanations of procrastination because accomplishing tasks on time may also depend on why one is pursuing the activity in the first place. The experienced supervisors interviewed as part of the University of Queensland study reflected upon this aspect of procrastination (Manathunga, 2002). As one supervisor, Sarah, suggested

If [a student is doing a $\mathrm{Ph} . \mathrm{D}$.] to please their mother or ... their father or they will have higher status in their country with this piece of paper, then that's the wrong reason and that will lead to a relatively poor outcome (Sarah, interview).

One theoretical construct that helps the supervisor investigate the reasons causing procrastination is that of the domains of learning (for example, Futoran, Hunt, \& Rivera, 1995). Brockbank and McGill (1998) specifically addressed the domains of learning involved in postgraduate supervision. They argued that these domains include the cognitive (thinking) domain, the conative (doing) domain, and the affective (feeling) domain. They linked these domains to supervisory functions, suggesting that supervisors have three significant roles: formative (educative); normative (administrative); and restorative (supportive) (Brockbank \& McGill, 1998, p. 239).

This analysis incorporates much of the recent literature on postgraduate supervision that seeks to move beyond a focus on the conative domain. Smith (2001) called the conative domain the "administrative framing" of supervision. Discussions of pedagogy often fall into three major theoretical or ideological paradigms: liberal pedagogy, critical pedagogy, and postmodernist pedagogy. In this exploration of supervision pedagogy, the majority of studies draw on either liberal or critical pedagogies. Liberal pedagogy places emphasis on developing the talents of individuals within existing society, where social systems are seen as the outcome of progressive, rational reform. Through a liberal curriculum, students are encouraged to have inquiring minds and to develop problem solving abilities. Critical pedagogy focuses on critiquing existing systems and practices and advocates changes to create a more 
peaceful and just society. Through a critical curriculum, students develop the ability to critique and to take action for change (Manathunga, 1997). Smith (2001) highlighted the fundamentally liberal philosophical basis to most of the literature on supervision. In this administrative or project management approach to supervision, supervisors' and students' individual roles and responsibilities are emphasized (Latona \& Browne, 2001). While these issues are important to ensuring students' continuing progression, they are only part of the complex role of a supervisor and do not really assist supervisors in identifying the particular origin of students' academic procrastination, which is much more likely to lie within the cognitive or affective domains, as our problem-solving model suggests (see Fig. 1).

Since the mid 1990s, there has been a growing recognition of supervision as a form of teaching or pedagogy (Acker, 2001; Connell, 1985; Green \& Lee, 1995; Smith, 2001). This has ensured that the cognitive domain of learning is now being identified and explored as a vital function of supervision. In particular, Pearson and Brew (2002) have applied the notion of "cognitive apprenticeship," first developed by Collins, Brown and Newman (1989), to postgraduate research supervision. They

\section{Figure 1}

\section{Domains Where Blocks Can Occur}

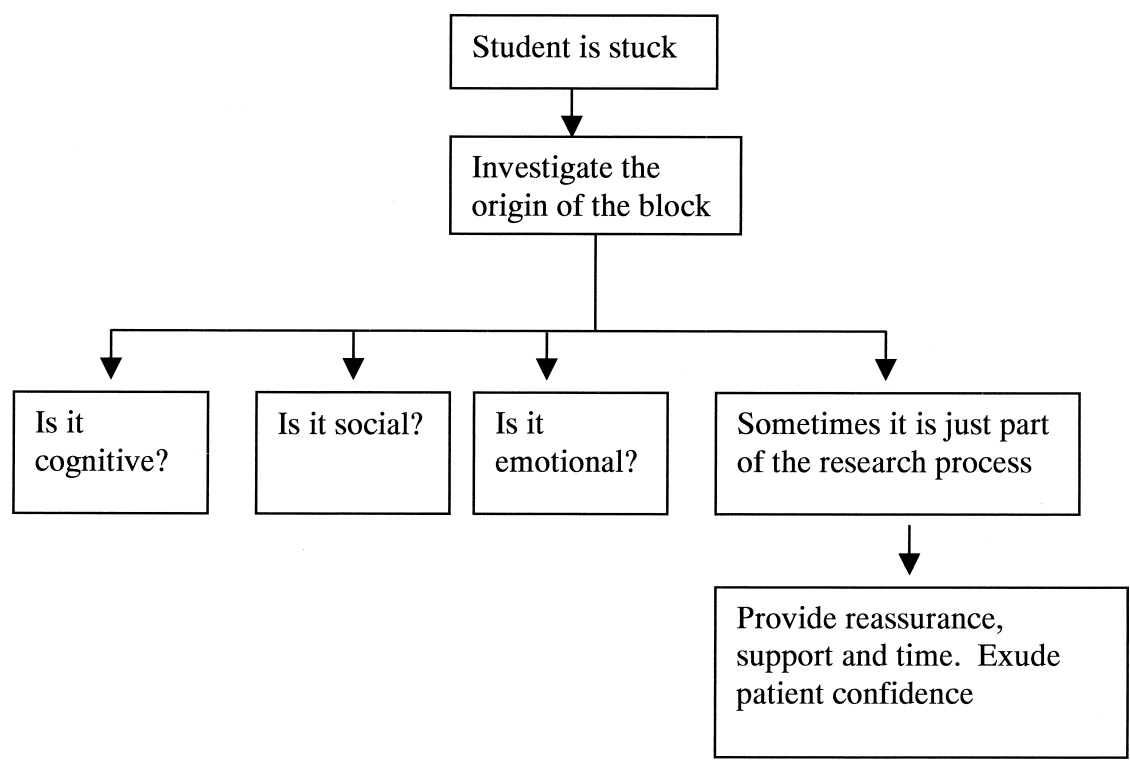


emphasised the importance of using key teaching strategies such as coaching, modelling, scaffolding, providing feedback, and mentoring to facilitate and enhance research students' learning. So, too, as our model demonstrates (see Fig. 1), exploring the cognitive domain is an important key to unlocking some of the causes of students' academic procrastination.

There has also recently been greater acknowledgement of the significant role the affective domain plays in research study and supervision (Cryer, 1996; Elphinstone \& Schweitzer, 1998; Glatthorn, 1998). Styles and Radloff (2000) carried out one of the most intensive studies of students' emotions about their research experience. In this study Styles and Radloff asked students to write or draw metaphors about their theses and to dscribe their feelings about their studies using a modified list of positive and negative adjectives originally developed by Zuckerman in 1960 (in Styles \& Radloff, 2000). They found that students' feelings about their theses were ambivalent even though they were predominantly positive. They suggested, therefore, that supervisors needed to be aware of this ambivalence and work with students to develop strategies to deal with both positive and negative emotions. Aspects of this study were replicated at the University of Queensland in 2002 (Manathunga, 2002), generating similar results. Parsloe (1993) produced a helpful table charting the range of different emotions students often experience at different stages of their candidature. These spanned the spectrum from relief, excitement, and confidence to anxiety, despair, and boredom, with the latter particularly clustered around the middle period of candidature.

The approach to identifying and addressing the causes of academic procrastination described in this article incorporates all three of these vital domains of learning in postgraduate study. If the supervisor systematically assesses each domain for a contributing factor to student procrastination, the cause/s can be identified and addressed. While the conative domain is important, our study found that the domains most likely to contain the underlying causes of a lack of progress at postgraduate level are the cognitive and affective (socio-emotional) domains. It is these domains that form the basis of our problem-solving model. The cognitive domain includes the student's ability to conceptualize, write, problem solve, and use academic resources efficiently. The affective domain can be divided further into emotional and social factors. Performance anxiety, low self-esteem, and personality clashes between supervisors and students make up the emotional factors, while social relationships and circumstances and academic and social integration are part of the social factors. 


\section{Identifying the Origin of Academic Procrastination}

A systematic approach to finding the origin of the block is recommended. Figure 1 provides an overview of the domains, which need to be investigated. It is possible that more than one domain will hold the cause of the block because many factors of student procrastination are interrelated (Becher, Henkel, \& Kogan, 1994; Lovitts, 2001; McNab, 1993; OECD, 1987).

\section{The Cognitive Domain}

Blocks in the cognitive domain (see Fig. 2) pertain to a lack of skills or knowledge essential for completion of a research thesis (Onwuegbuzie \& Collins, 2001). However, it is unusual for a student to declare such gaps in knowledge because the need for a positive self-presentation is ubiquitous (Schutz, Drogosz, White, \& Di Stefano, 1998). As students in the University of Queensland study (Manathunga, 2002) indicated, they were often reluctant to discuss their inability to complete some research tasks with their supervisors for fear of not "looking professional." One student exclaimed, "deep down we want to impress them [supervisors]" (focus group transcript). As a result, many students did not want to admit to their supervisors that they did not understand how to do a literature review, start writing, or perform other research tasks (focus groups \& support staff interviews). It has been our experience that students are more likely to invoke strategies to try to conceal their lack of knowledge; and, ironically, it is these strategies that are diagnostic (Ahern, 2000).

The ways students present themselves can provide clues to this concealment. According to Schutz, Drogosz, White, \& Di Stefano (1998), there are four styles of self-presentation. Assertive self-presentation consists of active, but not aggressive, efforts to build positive impressions, such as ingratiation, opinion conformity, helping others while neglecting one's own interests and self-promotion. Offensive selfpresentation is an aggressive way of trying to look good by making others look bad and includes critical evaluations of a third party. Such statements create the impression of a sharp mind that sets tough standards of evaluation. Another offensive form of self-presentation includes a person's attempts to change the topic of discussion in order to control the interaction and keep topics at bay that do not allow them to create the desired impression. A third style, protective selfpresentation, is geared to trying not to look bad. People engaging in 


\section{Figure 2 \\ The Cognitive Domain}

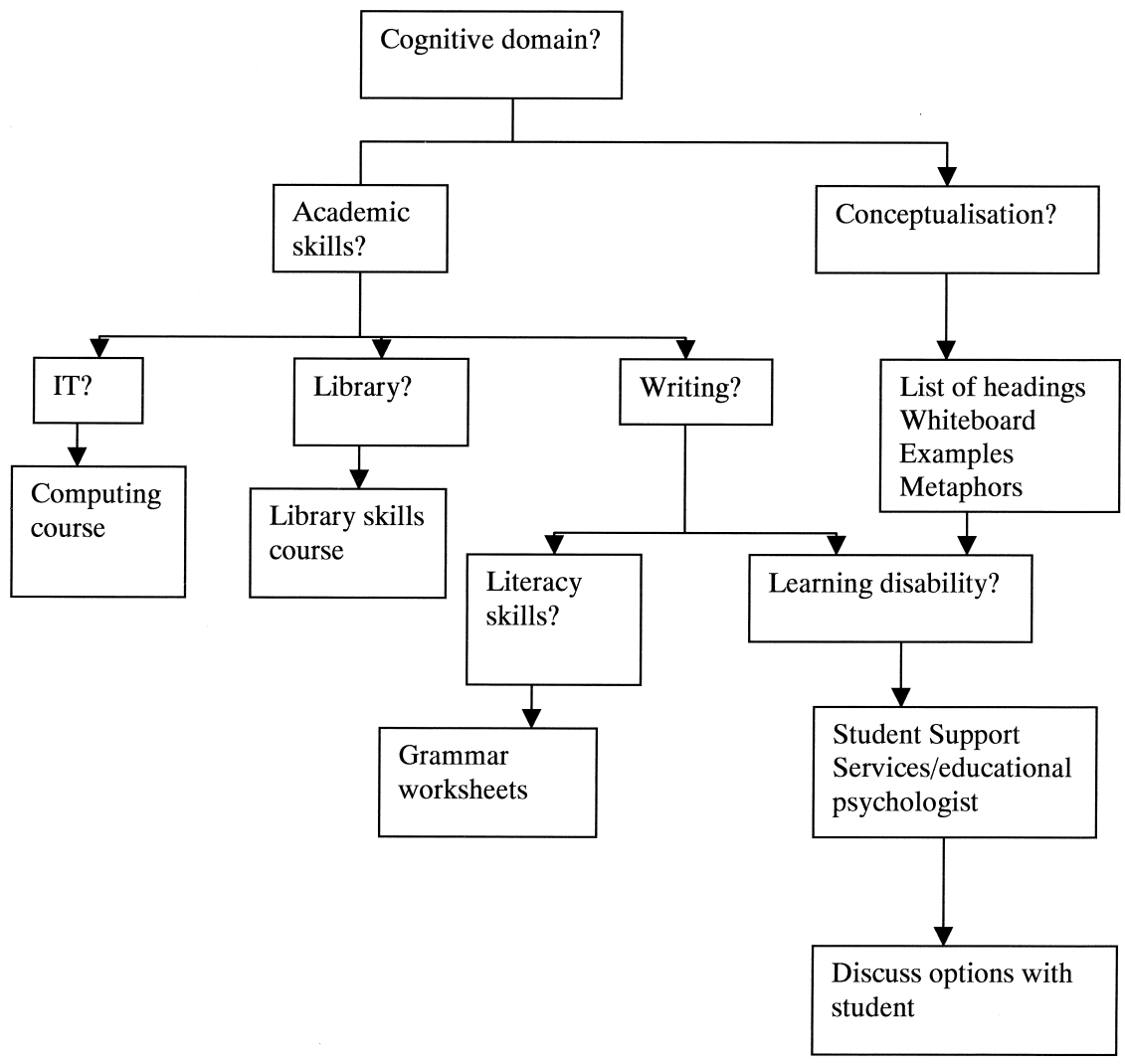

protective self-presentation often avoid situations that could be embarrassing or humiliating, and they seek passive but friendly interactions. The fourth style, defensive self-presentation, includes the use of denial, excuses, and justification. If the supervisor feels that interactions with the student conform to one or more of these self-presentation styles, this suggests that the student is blocked but is trying to hide this from the supervisor.

We have found that the best approach with students who we suspect have a cognitive reason for not making any progress is to ask directly, in a matter of fact, non-threatening way after a reasonable level of rapport and trust has been developed. We keep a list of skills courses available to students so we can reassure them that a lack of knowledge or skills 
is very common and fixable. Thus, if students are lacking necessary skills such as basic writing, ${ }^{3}$ statistical or library skills, the most effective solution is to require that the student attend courses to address the skills deficit. These courses can also address conceptualization skills although supervisors can also model their thought processes and thereby provide the type of cognitive apprenticeship Pearson and Brew (2002) recommended.

However, this does not mean that the student is automatically "unblocked." There could be a number of reasons why the student was unable to recognize or admit to having cognitive difficulties. One such reason could well be an emotional one like low self-esteem. For example, Onwuegbuzie (1999, in Onwuegbuzie \& Collins, 2001) reported that graduate students with the lowest perceived scholastic competence and perceived creativity tended to have the highest anxiety about writing. Often, however, it is difficult to differentiate cause and effect (Byrne, 1984).

\section{The Affective Domain}

Emotional blocks may be caused by performance anxiety, poor selfesteem, or a personality clash between supervisors and students (see Fig. 3). In our experience, many of the anxieties students have about their cognitive performance are based on distorted perceptions as much as on objective self-assessment (Greenberger \& Padesky, 1995). This is one of the most common emotional blocks we have encountered in postgraduate students, both male and female. As Ferrari \& Beck (1998) found, procrastinating students were often over-concerned about the amount of time needed for a particular research task. Performance anxiety can also be related to a misunderstanding of the purposes of Ph.D. study. If Ph.D. study is regarded by students primarily as a test of intelligence, the psychological implications of failure are enormous. Parsloe (1993) found that many women in particular embarked on research higher degree study in "an attempt to convince themselves that they are actually intellectually competent" (p. 51). If distorted students' perceptions of research tasks, their own ability, or the purposes of research study are identified as the basis of the procrastination, the technique of reframing is useful. If the student can view the postgraduate research project as a series of hoops to jump through, rather than a test

${ }^{3}$ Common problems experienced by graduate students include lack of a clear topic sentence for each paragraph, organization of the argument, and run-on sentences. 


\section{Figure 3 \\ The Emotional Domain}

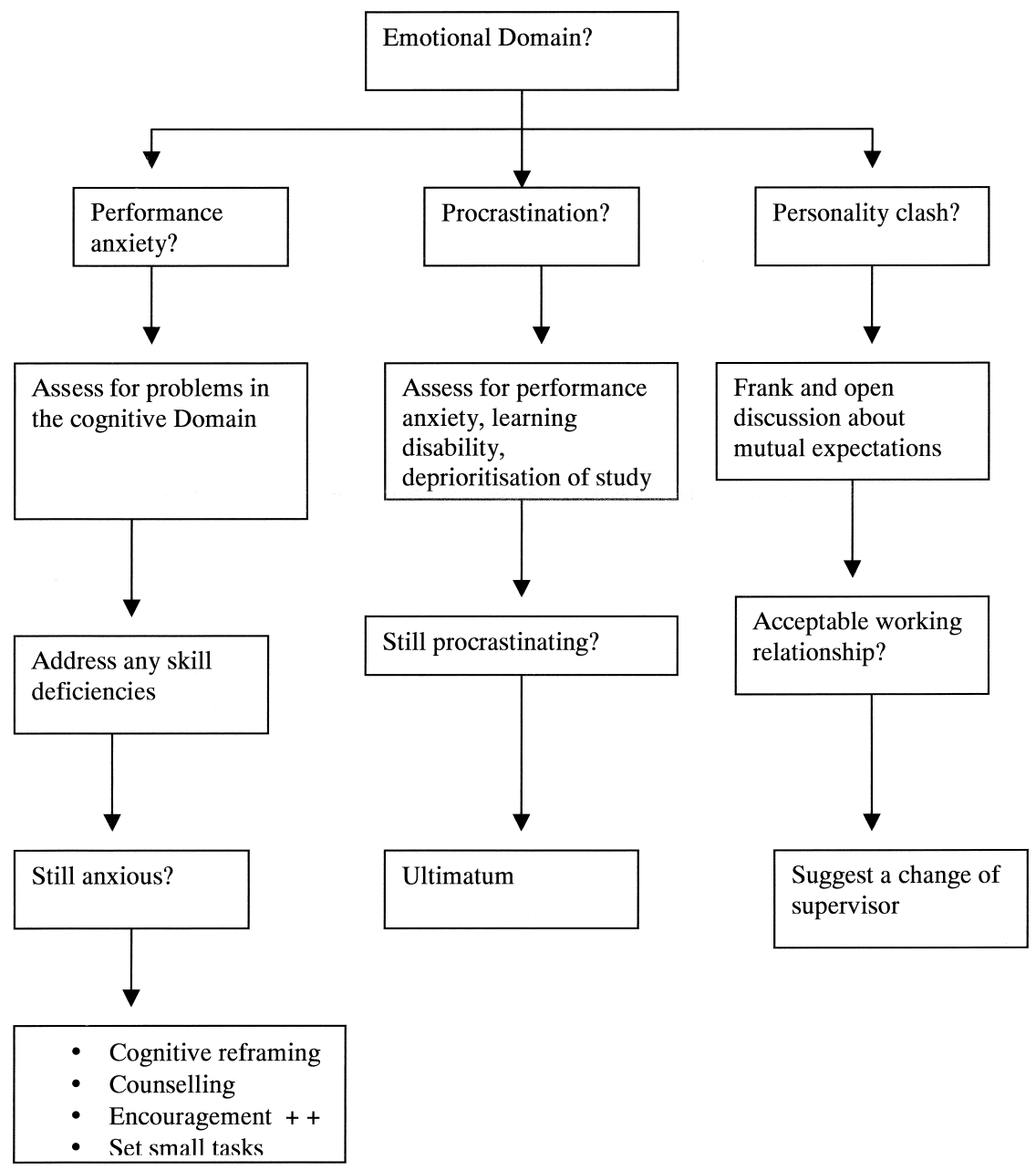

of intelligence, the devastating consequences to their sense of self of encountering problems or performing tasks are minimised.

We prefer to employ the efficient yet whimsical strategy of "reframing." We give two jars to our anxious research students. One jar is filled with brightly coloured buttons, the other jar is empty. The number of buttons in the filled jar depends on the length of thesis required and 
represents the number of hoops the student must jump through. For example, a Ph.D. represents 200 buttons, while a masters degree is equivalent to 100 . Every problem, deadline, or task represents a hoop. Every time a task is completed or a problem is overcome, the student can put a button from the full jar into the empty jar. When all the buttons have been transferred, the Ph.D. will be finished. In this way the Ph.D. is reconceptualised as a series of tasks that do not reflect upon the intelligence or value of the student. The play-like quality of this activity belies its potency and the immediacy of its effect.

However, for some situations re-framing a thesis into a game or a series of achievable tasks is not effective. For some students, we have found it necessary to reframe a procrastination problem into an issue of self-preservation for the student. When all else fails, an ultimatum regarding termination of the course of study may provide a procrastinating student with the powerful motivator of self-preservation. In other words, the fear of having one's work found to be potentially unacceptable is not as bad as the reality of failing, so the student pursues the lesser evil of presenting drafts, or commencing data collection, for example.

Another emotional block may be related to a student's poor sense of self-esteem. While this can be related to a range of personal factors, attempting to build students' confidence in their research abilities is something supervisors can implement in order to address students' self esteem problems. In the University of Queensland study, Manathunga found that the experienced supervisors she interviewed perceived building their student's confidence as a fundamental teaching and learning strategy. Extending the reframing strategy described before, one supervisor emphasized the need to assist students to break their research down into "small chunks" or milestones, especially those that could lead to publishable outcomes (Mary \& Bill, Interviews).

Another strategy to build students' confidence is to ensure that students leave each supervision meeting "feeling that they have accomplished something ... even if it is small" (Mary, Interview). This involves "conveying [your own] sense of confidence in the student... [and] finding the strengths and real possibilities of this thesis and what might be really unique about it and how it might contribute" (Mary, Interview). Identifying these possibilities and strengths is an important part of the supervisor's job in the early stages of a student's candidature, as Mary suggested (Interview). Sarah described this process as "helping [students] achieve their potential" and argued that a number of her students were perceived by other academics as "cast offs... [students 
who had] been pigeon-holed as not being Ph.D. material." With her support, Sarah was able to "let them out of this pigeon-hole." One example that clearly demonstrated Sarah's success in providing a supportive environment within which students can develop was the story of a Thai student, whom we shall call Beth. As Sarah recounted,

Beth was so quiet in the beginning... and now she's actually the boss in the lab.... She's got this natural leadership and she's the bubbliest [person]. She's very organized and extremely hardworking ... and the others all respect her. She's not the most senior person but she's ... a natural leader.

An important aspect of building students' confidence is also to break down the sense of isolation that can be part of research, particularly in the humanities and social sciences where individual research is much more common. This involves framing supervision as a collaborative problem solving exercise, whereby students receive the message that they are not alone in this "most daunting academic marathon of their lives" (Mary, Interview). This sense of running this race together is encapsulated in Mary's (Interview) exclamation- "We've got it! We've solved that problem!"

One supervisor highlighted the gendered dimensions of student confidence which have been discussed in various studies (Conrad, 1994; Nightingale \& Sohler, 1994) and which link with Yeatman's (1995) argument that women (and other non-dominant groups) have not been encouraged to think themselves worthy of being "the subjects of [a supervisor's] genius" (p. 9). This research suggests a persistent pattern of women underestimating their ability, which has been confirmed by other studies, such as that conducted by Minnaert (1999) and Ahern, Dixon, Hauck, Jackiewicz and Jones (1994). In supervisor Mary's experience this phenomenon has emerged in "hearing hints from women that they are not sure that they are good enough" (Interview). Mary's strategy for dealing with this issue is to "make sure... even before I hear [these hints] ... that they get the message that they ... can do this" (Interview).

Another key source of emotional blockage could be a personality clash between the supervisor and the student. This can result from a clash of unclear, unrealistic or unnegotiated expectations of each other. Aspland, Edwards, O'Leary, and Ryan (1999) emphasized the importance of honestly negotiating the expectations of all the parties in the supervision relationship, including associate supervisors. They also developed a very useful instrument, the Role Perception Rating Scale (Aspland et al., 1999), which can be used to open up space in supervisory 
sessions for a frank dialogue about mutual expectations. This tool in particular helps to flag key areas of incongruence between the implicit expectations students and supervisors may have of each other.

A personality clash may also result from different approaches to learning and research. Gurr (2001) highlighted the potential for a clash to develop between the student's learning needs and their supervisor's teaching style. He developed a Supervisor/Student Alignment tool kit that allows students and supervisors to plot where they are and where they think the student or supervisor is on an axis of dependence to competent autonomy for students and a hands-on to hands-off axis for supervisors. This allows them to identify potential differences between the student's needs and supervisor's style, to ascertain whether the relationship is at an appropriate level for the student's stage of candidature, and to uncover any differences in perception about the other person's perceived position. Essentially, this instrument promotes a frank discussion of needs and styles, and using it can help diagnose potential clashes before they happen.

A personality clash between supervisors and students may also arise from different implicit conceptions of research. As Brew (2001) discovered, supervisors have vastly different conceptions of research. Brew identified four such conceptions, which spanned the disciplines. Supervisors are often unaware of their implicit conception of research and equally unaware that students may have an entirely different perception. As Pearson and Brew (2002) subsequently suggested, therefore, it is important for supervisors to recognise their own underlying conception of research, to explore students' conceptions, and to discuss explicitly any differences that may impact on the supervision relationship.

\section{The Social Dimension}

Some of the blocks to a student's progress may occur in the student's personal relationships and social circumstances, impinging on the student's ability to devote the necessary time to their research. They can also occur when students are not adequately integrated into the school's research culture (see Fig. 4).

Experiencing a lack of integration with the department's research culture may also be an underlying social cause of student procrastination. Lovitts (2001) divided the types of integration students need to experience if they are to complete their studies in a timely way into academic and social integration. She argued that students need to become part of the collective community of the department and become 


\section{Figure 4 \\ The Social Domain}

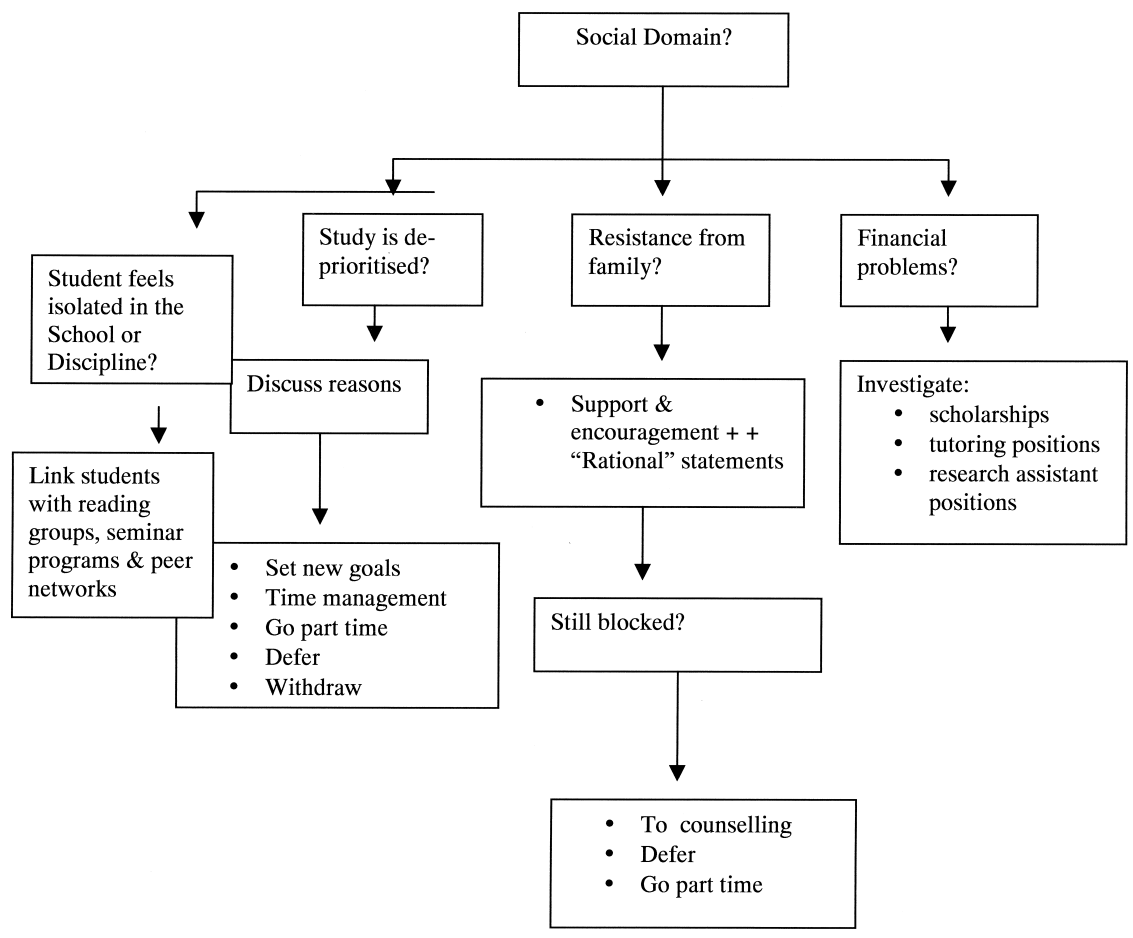

familiar with its disciplinary practices. In order to do this, students not only need to engage in intellectual and professional tasks with other students and faculty members but also to join in formal and informal social activities that generate a feeling of belonging. The importance of helping students to become part of the research culture of the discipline and to become part of a supportive student peer group were emphasised by supervisors in the University of Queensland study (Manathunga, 2002). Supervisors interviewed in this study established research or reading groups and more formal seminar programs as an important way of incorporating their students into a supportive research culture.

Becoming integrated into the research culture is especially problematic for students who are employed full-time and are parents of children (Grossman, Gooden, Wavelet, Diaz, \& Seupersad, 2002). Some studies have also identified gender dimensions to the issue of competing 
demands for research students' time. For example, Lovitts' (2001) U.S. study highlighted the differing kinds of responses experienced by men and women with family commitments or difficulties. While male students were provided with more support and understanding if they had difficulties in their home lives, these same difficulties were perceived as evidence of divided loyalties by women students. If the student is wrestling with competing time demands, the supervisor will need to help the student assess whether the level of commitment to his/her studies is realistic given these demands. Assuming that the student's motivation to study remains high, remedies for supplying more time for studies include deferring studies or reducing the load to part time (Gigliotti \& Gigliotti, 1998).

Other major family changes or difficulties can also disrupt student's study. This was shown in Lovitts' (2001) study, in which she found that relationship breakdowns particularly resulted in women withdrawing from research higher degree studies, while unsatisfying but continuing relationships resulted in men leaving their studies. Marriage or a partner moving away from the area impacted more on women than men, often resulting in them leaving their studies. Lovitts (2001) also found that unexpected or even planned pregnancies often resulted in women withdrawing from research studies.

Another source of social blockage can occur when there is resistance from the student's family members. Jealousy of a partner may result in explicit or implicit attempts to derail a student's progress. This was a problem experienced by more female students than male students in the University of Queensland study (Manathunga, 2002). For example, Bill, a supervisor, reported that it was not uncommon for female students to indicate that "my husband's not supporting me," while none of his male students had commented on experiencing such an obstacle. He speculated that this was perhaps a result of "male envy when they're doing well or they are getting to a point that they haven't [achieved]" (Bill, interview). In these cases, the decision of whether to succumb to overt and covert attempts to sabotage their studies must be made by the students, and there is little the supervisor can do except provide support and perhaps recommend counselling or deferring studies. The supervisor can also seek to model more realistic patterns of behaviour in juggling work, family and study commitments. For example, by commenting briefly on their own strategies for managing their research, supervisors can assist students to set more realistic goals for themselves. We suggest that students assess which time of the day they are most able to devote productive brain time to their studies (such as first 
thing in the morning) and plan to accomplish writing and difficult conceptual work during these times. Then they can allocate other times when they are likely to be very tired to less demanding tasks, such as answering emails. We also suggest that they establish small but realistic goals, such as reading one article per day, if they are trying to juggle other work and/or family commitments.

Financial difficulties can also impede students' progress and the amount of time they are able to devote to their studies. Manathunga's (2002) study indicated that some students were particularly reluctant to discuss these kinds of difficulties with their supervisors. In some cases, students felt that it was shameful to have to admit they needed "to work to pay the bills" (Molly, focus group), suggesting that either supervisors had forgotten what it was like to be a student or that they had never experienced these pressures. If we, as supervisors, believe that a student is experiencing financial difficulties, we are prepared to assist them in looking for additional scholarships or sources of money, such as tutoring or research assistant work and so on. We also refer them to student support services and counselling for further assistance.

\section{Conclusion}

Although we propose this systematic approach to identifying and overcoming student blocks, we recognize that real life is rarely as neat as Fig. 1 indicates (McWilliam, Singh, \& Taylor, 2002). Firstly, all the domains interact, so fixing a block in one domain might not correct the procrastination problem. Secondly, we have proposed a problem solving process as a linear series of steps. In fact, postgraduate supervision is an ongoing process; and different blocks to research can occur throughout the entire supervision relationship, which will present themselves in different ways. Finally, we have developed these guidelines after years of supervising postgraduate students and reading the extant literature in the field of postgraduate education. We do not view them as a proscriptive set of rules, nor do we see them as complete, as we continue to learn new ways to be better supervisors from our students.

Academic procrastination is, however, an emotionally expensive and self-defeating strategy for research students and the sooner it can be identified and addressed, the better. Blocks in research can occur in cognitive, social and emotional domains and are often overlapping. By using a systematic approach to test hunches about the origins of the block, supervisors can at least try to provide appropriate intervention to get the student moving again. 


\section{References}

Acker, S. (2001). The hidden curriculum in dissertation advising. In E. Margolis (Ed.), The hidden curriculum in higher education (pp. 61-77). New York, NY: Routledge.

Ahern, K. (2000). "Something is wrong with my child": A phenomenological account of a search for a diagnosis. Early Education and Development, 11, 124-138.

Ahern, K., Dixon, C., Hauck, Y., Jackiewicz, S., \& Jones, B. (1994). Aspects of confidence in research activity. Third National Conference of Women in Leadership, Perth, Western Australia. Perth: Edith Cowan University.

Aspland, T., Edwards, H., O'Leary, J., \& Ryan, Y. (1999). Tracking new directions in the evaluation of postgraduate supervision. Innovative Higher Education, 24, 127-147.

Becher, T., Henkel, M., \& Kogan, M. (1994). Graduate education in Britain. London: Jessica Kingsley.

Beswick, G., Rothblum, E. D., \& Mann, L. (1988). Psychological antecedents of student procrastination, Australian Psychologist, 23, 207-217.

Black, A., \& Deci, E. (2000). The effects of instructors' autonomy support and students' autonomous motivation in learning organic chemistry: A self-determination theory perspective. Science Education, 84, 740-756.

Brew, A. (2001). Conceptions of research: A phenomenological study. Studies in Higher Education, 26, 271-285.

Brockbank, A., \& McGill, I. (1998). Facilitating reflective learning in higher education. Buckinghan, England: SRHE \& Open University Press.

Byrne, B. (1984). The general/academic self-concept normological network: A review of construct validation research. Review of Educational Research, 54, 427-456.

Collins, A., Brown, J., \& Newman, S. (1989). Cognitive apprenticeship: Teaching the crafts of reading, writing and mathematics. In L. Resnick (Ed.), Knowing, learning, and instruction: Essays in honor of Robert Glaser (pp. 453-494). Hillsdale, NJ: Erlbaum.

Connell, R. (1985). How to supervise a Ph.D. Vestes, 28(2), 38-42.

Conrad, L. (1994). Gender and postgraduate supervision. In O. Zuber-Skerrit \& Y. Ryan (Eds.), Quality in postgraduate education (pp. 51-58). London: Kogan Page.

Cryer, P. (1996). The research student's guide to success. Buckingham, England: Open University Press.

Deem, R., \& Brehony, K. J. (2000). Doctoral students' access to research cultures-Are some more unequal than others? Studies in Higher Education, 25, 149-164.

Elphinstone, L., \& Schweitzer, R. (1998). How to get a research degree: Survival guide. London: Allen \& Unwin.

Ferrari, J., \& Beck, B. (1998). Affective responses before and after fraudulent excuses by academic procrastinators. Education Summer, 118(4), 529-538.

Futoran, G., Hunt, J., \& Rivera, J. (1995). The temporal impact of management faculty style and course characteristics: Some theoretical and developmental implications. Group and Organization Management, 20, 310-336.

Gigliotti, R., \& Gigliotti, C. (1998). Self concept of academic ability and the adult college student. Sociological Inquiry, 68, 295-322.

Glatthorn, A. (1998). Writing the winning dissertation. Thousand Oaks, CA: Sage.

Green, B., \& Lee, A. (1995). Theorising postgraduate pedagogy. Australian Universities Review, 2, 40-45.

Greenberger, D., \& Padesky, C. (1995). Mind over mood. New York: Guilford Press.

Grossman, L., Gooden, S., Wavelet, M., Diaz, M., \& Seupersad, R. (2002). Opening doors: Students' perspectives on juggling work, family and college. New York: Manpower Demonstration Research Corporation.

Gurr, G. (2001). The supervisor student alignment tool kit. Retrieved February 21, 2003, from fIRST consortium Web site for improving research supervision and training: http://wallace.iim.uts.edu.au/staging/first/index.html

Johnson, E. M., Green, K. E., \& Kleuver, R. C. (2000). Psychometric characteristics of the revised procrastination inventory. Research in Higher Education, 41, 269-279. 
Kearns, H. (2002). Sabotage: How we do it and what you can do about it (abstract). In M. Kiley \& G. Mullins (Eds.), Quality in postgraduate research: Integrating perspectives conference proceedings, Adelaide, April 18-19, 2002 (p. 175).

Adelaide, Australia: Advisory Centre for University Education, The University of Adelaide.

Latona, K., \& Browne, M. (2001). Factors associated with completion of research higher degrees (Governmental report in 'Higher Education Series' 37). Canberra, Australia. Department of Education, Training and Youth Affairs, Higher Education Division.

Lovitts, B. E. (2001). Leaving the ivory tower: The causes and consequences of departure from doctoral study. Lanham, MD: Rowman \& Littlefield.

Manathunga, C. (2002). Detecting and dealing with early warning signs in postgraduate research education: A work-in-progress. In M. Kiley \& G. Mullins (Eds.), Quality in postgraduate research: Integrating perspectives conference proceedings, Adelaide, April 18-19, (pp. 80-88). Adelaide, Australia: Advisory Centre for University Education, The University of Adelaide.

McNab, B. (1993). Perceptions of phobia and phobics: The quest for control. San Diego, CA: Academic Press.

McWilliam, E., Singh, P., \& Taylor, P. (2002). Doctoral eduction, danger and risk management. Higher Education Research and Development, 21, 119-129.

Minnaert, A. (1999). Motivational and emotion components affecting male's and female's self-regulated learning. European Journal Psychology of Education, 14, 525-540.

Muszynski, S., \& Akamatsu, T. (1991). Delay in completion of doctoral dissertations in clinical psychology. Professional Psychology: Research and Practice, 22, 119-123.

Nightingale, P., \& Sohler, C. (1994). Considering gender. Campbelltown, Australia: HERDSA.

OECD. (1987). Postgraduate education in the 1980s. Paris: Organisation for Economic Co-operation and Development.

Onwuegbuzie, A., \& Collins, K. (2001). Writing apprehension and academic procrastination among graduate students. Perceptual and Motor Skills, 92, 560.

Parsloe, P. (1993). Supervising students for higher degrees by research in a social work department. Journal of Further and Higher Education, 17, 49-60.

Pearson, M., \& Brew, A. (2002). Research training and supervision development. Studies in Higher Education, 27(2), 135-150.

Rothblum, E., Solomon, L., \& Murakami, J. (1986). Affective, cognitive, and behavioral differences between high and low procrastinators. Journal of Counselling Psychology, $33,387-394$.

Schapiro, S., \& Livingston, J. (2000). Dynamic self-regulation: The driving force behind academic achievement. Innovative Higher Education, 25, 23-35.

Schutz, P., Drogosz, L., White, V., \& Di Stefano, C. (1998). Prior knowledge, attitude, and strategy use in an introduction to statistics course. Learning and Individual Differences, 10, 291-308.

Senécal, C., Koestner, R., \& Vallerand, R. (1995). Self-regulation and academic procrastination. Journal of Social Psychology, 135, 607-619.

Smith, B. (2001). (Re)Framing research higher degree supervision as pedagogy. In A. Bartlett \& G. Mercer (Eds.), Postgraduate research supervision: Transforming (R)Elations (pp. 25-41). New York: Peter Lang.

Solomon, L., \& Rothblum, E. (1986). Stress, coping, and social support in women. Behavior Therapist, 9, 199-204.

Style, I., \& Radloff, A. (2000). Jabba the Hut: Research students' feelings about doing a thesis. In A. Hermann \& M. M. Kulski (Eds.), Flexible futures in tertiary teaching. Proceedings of the 9th Annual Teaching Learning Forum, February 2-4, 2000. Perth, Australia: Curtin University of Technology.

Yeatman, A. (1995). Making supervision relationship accountable: Graduate student logs. Australian Universities Review, 1995(2), 9-11. 